University of New Mexico

UNM Digital Repository

University Libraries \& Learning Sciences Faculty

and Staff Publications

Academic Department Resources

2010

\title{
Predictors of Learner Satisfaction and Transfer of Learning in a Corporate Online Education Program
}

\author{
Charlotte Nirmalani Gunawardena \\ University of New Mexico, lani@unm.edu \\ Jennifer Linder-VanBerschot \\ University of New Mexico \\ Deborah LaPointe \\ University of New Mexico \\ Lalita Rao \\ University of New Mexico
}

Follow this and additional works at: https://digitalrepository.unm.edu/ulls_fsp

Part of the Online and Distance Education Commons

\section{Recommended Citation}

Gunawardena, C.N., Linder-VanBerschot, J. A., LaPointe, D. K., Rao, L. (2010). Predictors of learner satisfaction and transfer of learning in a corporate online education program. The American Journal of Distance Education, 24(4), 207-226.

This Article is brought to you for free and open access by the Academic Department Resources at UNM Digital Repository. It has been accepted for inclusion in University Libraries \& Learning Sciences Faculty and Staff Publications by an authorized administrator of UNM Digital Repository. For more information, please contact amywinter@unm.edu, Isloane@salud.unm.edu, sarahrk@unm.edu. 
Citation:

Gunawardena, C.N., Linder-VanBerschot, J. A., LaPointe, D. K., Rao, L. (2010). Predictors of learner satisfaction and transfer of learning in a corporate online education program. The American Journal of Distance Education, 24(4), 207-226.

\section{PREDICTORS OF LEARNER SATISFACTION AND TRANSFER OF LEARNING IN A CORPORATE ONLINE EDUCATION PROGRAM}

Charlotte N. Gunawardena, Jennifer A. Linder-VanBerschot, Deborah K. LaPointe*, and Lalita Rao

University of New Mexico

* Deborah K. LaPointe (1952-2009) 


\begin{abstract}
This study explores factors that predict learner satisfaction and transfer of learning in an online educational program at a multinational corporation, established to improve organizational learning through providing training in technical skills. A mixedmethods design was employed, selecting both quantitative methods utilizing survey research and qualitative methods employing open-ended questionnaire items, face-to-face and phone interviews, gathering the perspective of students, instructors, and instructional designers. The online courses were designed using a problem-centered and case-based approach to learning, and utilized technologies including Learning Management Systems such as Blackboard, Sharepoint, as well as instructional design tools such as Breeze, Captivate and PowerPoint. Online self-efficacy emerged as the strongest predictor of learner satisfaction; collegial support was the strongest predictor of transfer of learning. Qualitative analysis provided additional insight on these findings and the elements that impacted the operation of an online education program in a corporate setting.
\end{abstract}




\section{PREDICTORS OF LEARNER SATISFACTION AND TRANSFER OF LEARNING IN A CORPORATE ONLINE EDUCATION PROGRAM}

Corporate universities regularly investigate how they can design and develop their own proprietary education and training for their employees. When companies have multiple sites in international locations, the Internet is considered a viable option to provide advanced education and technical training at a time and place that is convenient for the employees. This study examines a multinational corporation's effort to use online education to train employees in technical skills. The research was undertaken to examine how online education can be a catalyst for organizational learning by training employees through work-related problem solving in technical areas. Using a mixed-method approach (Creswell and Clark 2007), the main purpose of this study was to determine the predictors of success of online learning, defined as learner satisfaction and transfer of learning.

\section{Background}

The College of Engineering (COE) Online Education program was an initiative of a large multinational corporation to train employees in technical skills. It was designed to replace traditional face-to-face training across national and international corporate sites, and was intended to increase engineering proficiency and expertise through rigorous, collaborative, and extended coursework in technical specialties. This online initiative in the $\mathrm{COE}$ was an evolving program in a changing organizational climate. COE courses were grounded in the instructional method of problem solving in authentic contexts, thus situating the learning in the corporate setting. The combination of synchronous and 
asynchronous technologies in each of the three courses studied, helped promote interaction and maintain flexibility for students and instructors, both domestic and overseas. Asynchronous tools included Blackboard and Sharepoint, while synchronous tools such as Net Meeting and audio teleconferencing were used for the instructor-led classes. Instructional design tools such as Breeze, Captivate, PowerPoint and video were used to develop the lessons.

The COE curriculum was designed to build upon the formal university education and technical job training that corporate engineers received. The COE program consisted of college-level courses at both the undergraduate and graduate levels. These courses were primarily developed by instructional designers and then taught by in-house engineers, typically on their own time and without compensation. COE courses incorporated authentic corporate manufacturing and engineering problems as case studies. Where appropriate, external experts provided feedback to assure course content was state-of-the-art and helped deliver the instruction. Classes were structured in a semester-length format, which included prerequisites and required course work and work-related projects.

\section{Review of Literature}

In a review of distance training in the corporate sector, Berge (2007) emphasized that in the global economy of the $21^{\text {st }}$ century, learning organizations are under increasing pressure to demonstrate that training and development directly contribute to the profitability of the organization. Yet, research on online education and training in the corporate sector are predominantly case studies, which describe specific contexts and 
programs (Homan and Macpherson 2005; Macdonald, Bullen, and Kozak 2007; Rabak and Cleveland-Innes 2006). The need to move beyond case studies in academia and industry to inferential and naturalistic studies that examine learner characteristics and variables in the online education process that lead to learning gains, transfer of learning, and satisfaction have been identified by researchers (Abrami and Bernard 2006; Burke and Hutchins 2007).

Since one of the prime drivers of corporate distance education programs is ROI, one outcome that is critical to assessing success is transfer of learning to the workplace, defined as the learner's ability to apply the skills and knowledge learned in the course to the workplace both during and after the course. Nevertheless, it is also important to assess the learner's experience and the likelihood that the learner would continue to enroll in corporate distance education courses. "Only when corporate universities address more fundamentally the issues of pedagogy and learner response to e-learning will they be in a position to claim that e-learning makes a significant contribution to their corporate university's strategy" (Homan and Macpherson 2005; p. 87). This study was designed to explore both learner satisfaction and transfer of learning, two outcome variables in the corporate online education context that have an impact on the success of the program.

\section{Learner Satisfaction}

Learner satisfaction was chosen as a dependent variable because students who report higher levels of learner satisfaction often participate more, demonstrate greater learning gains, and continue to enroll in online classes (Allen et al. 2007). If students are satisfied, they are more likely to be successful (Puzziferro 2008). Satisfaction informs how e-learning is received, accepted, and valued, and attests to the quality of the learning 
experience.

Variables associated with learner characteristics such as learner self-efficacy and motivation, and online education process variables such as learner support, interaction, technology, course design, and social presence, have been shown to impact achievement and satisfaction with learning (Arbaugh and Hiltz 2005; Burke and Hutchins 2007; Goldman et al. 2005; LaPointe and Gunawardena 2004; Lim 2001; Puzziferro 2008). Given previous research and the corporate context we studied, we resolved to focus on four variables that have the likelihood of impacting learner satisfaction in this corporate setting: online self-efficacy, course design, learner-learner interaction and learnerinstructor interaction.

In the online context, one important aspect of self-efficacy (Bandura 1995) is related to the learner's confidence in using technology to engage in learning. Researchers have investigated learner's self efficacy related to online technologies as predictors of learning or satisfaction (Park and Wentling, 2007; Wang and Newlin 2002). Computer self-efficacy was found to be the most significant factor affecting user's acceptance of online education in high-tech companies (Ong et al. 2004). On the other hand, DeTure (2004), and more recently Puzzifero (2008) reported that self-efficacy scores related to online technologies were not related to student performance in college-level online courses. Given that the population in this study was technologically savvy, this was an important variable to resolve and examine in a predictive model of satisfaction.

In order for distance education to become an integral part of an organization's culture there must be a general sophisticated understanding of the requirements for quality design, delivery and learner support (Moore 2006). Garrison and Cleveland- 
Innes' (2005) study showed the importance of designing interaction, clearly defining course expectations, selecting manageable content, structuring appropriate learning activities and conducting assessments congruent with learning goals in order to foster an online environment conducive to learning.

The concept of interaction, or the communication process in online education has generated much discussion and debate (Juwah, 2006). Rhode's (2009) study found that learners preferred learner-instructor and learner-content interaction rather than learnerlearner interaction. On the other hand, Belanich, Wisher, and Orvis' (2004) study of collaborative question writing on learner outcomes in a distributed learning environment in three army schools indicated that collaboration supported the learning process. Dobrovolny (2006) showed that adult learners frequently used conversations to learn from self-paced technology-based corporate training, which suggests that dialog and discussion are important in the design of these new ways of learning. LaPointe and Gunawardena's (2004) study showed that students who reported participating more in online discussions perceived a direct impact on their learning outcomes. Given the varied perspectives on interaction, examining this variable in a corporate setting was important for this study.

\section{Transfer of Learning}

Lobato (2008) noted that there is little agreement among researchers about the nature of transfer, the extent to which it occurs, and the nature of its underlying mechanisms. However, transfer of learning is a critical variable in research conducted in corporate settings, as the goal of training is to enhance work performance. The Baldwin and Ford (1988) transfer model and the conceptual model of Holton (1996), and Holton 
Bates and Ruona (2000) are the most commonly cited and used in transfer studies (Lim and Morris 2006). After a thorough review of literature, Baldwin and Ford (1988) developed a training transfer construct composed of three factors: trainee characteristics (ability, personality, motivation, and organizational commitment); training design (the extent to which the course design supports transfer); and work environment characteristics or transfer climate (peer support, supervisor support, and opportunity to use). This model explains the transfer phase in three phases: training input factors, training outcomes, and conditions for transfer. Given our corporate context, we found the Baldwin and Ford (1988) transfer model more applicable to our study, as it provided a comprehensive view of the transfer constructs, especially the organizational climate that supported transfer. Organizational climate variables are those work and environmental factors that inhibit, reduce, and/or promote training transfer (Lim and Morris 2006).

The impact and transfer of learning from the classroom to the workplace is often contingent upon the nature of the transfer climate (Homan and Macpherson 2005; Burke and Hutchins 2007). Lim and Morris' (2006) study found that organizational climate was one influential variable for trainees' perceived application of learning. Conrad (2008) showed that the supervisor's interest was connected to or predicated the potential transfer of learner's new knowledge to the workplace. Examining the relationship between organizational climate variables and transfer of learning was an important goal of this study.

\section{Research Context and Questions}

This study was designed to examine predictors of learner satisfaction and transfer 
of learning in online education courses in a corporate setting by gathering evidence from learners enrolled in the courses, their instructors, and the instructional designers using a mixed-methods research design. The primary research questions guiding the study were:

1. What factors predict learner satisfaction in the COE online courses?, and

2. What factors predict transfer of learning to the workplace?

\section{Method}

The study was conducted on an evolving program in a changing organizational climate, which required flexibility in the research process. The study design used a mixed-methods approach employing both quantitative and qualitative analysis. Creswell and Clark's (2007) convergence model was used to structure the data analysis for this mixed-methods study. In this version of the triangulation design, researchers collect and analyze quantitative and qualitative data separately, then compile the results during interpretation. This method was chosen as most appropriate so that the quantitative and qualitative results could be compared and validated.

Based on our review of literature and the corporate context studied, we selected four independent variables (online self-efficacy, course design, learner-instructor interaction, and learner-learner interaction) in our model to predict learner satisfaction in three COE courses. Online self-efficacy is the belief that one has the confidence to learn online, and was measured by the learner's confidence in using technology to participate in the online course, the ability to learn from online course discussions, and the confidence to transfer learning from the online environment to the workplace. Course design refers to the structure of the course, and refers to clarity of objectives, instructions and teaching materials, which incorporated case studies based on corporate problems. 
Interaction between the learner and the instructor and between learners relates to the process of learning and communication in an online course. Learner-instructor interaction was measured by access to the instructor, prompt responses to questions, and useful feedback. Learner-learner interaction measured the usefulness of dialoguing with other learners, interest in topics under discussion, and communication with colleagues at the site. The dependent variable was learner satisfaction and is defined as the learner's perception that the course was a beneficial experience that he or she will recommend to others. Student input to two open-ended questions in the survey provided further information on factors that contributed to satisfaction or frustrations that detracted from satisfaction.

In the quantitative analysis, we adapted Baldwin and Ford's (1988) model to predict transfer of learning in the corporate context, focusing on organizational climate factors that either support or detract from transfer of learning. The independent variables were collegial support, organizational support, manager support and organizational incentives. Collegial support refers to the support and value given to the learner by his or her coworkers to transfer new learning. Organizational support is defined as the culture of the organization to promote online learning throughout the organization as a means of maintaining and developing a skilled workforce in a competitive market. Manager support refers to the manager's value and promotion of the learner's participation in the course as reflected by setting goals to apply the knowledge and skills learned to the workplace and making it possible for the learner to attend the course. Organizational incentives are defined as the factors that provide a motive for employees to take a particular course of action, in this case, to enroll in and complete the online courses. The 
dependent variable was transfer of learning and is defined as the learner's ability to apply the skills and knowledge learned in the course to the workplace both during and after the course. The qualitative analysis examined transfer from a more open-ended perspective focusing on students' input in open-ended questions, and instructors' input in interviews on how transfer of learning occurred.

\section{Participants}

Participants were engineers, technicians, group leaders, and managers from the corporation's United States and international sites. All participants had enrolled in at least one of three online education courses included in this study. The corporation did not allow the researchers to gather demographics on gender, age, ethnicity or nationality, so we are unable to report on that information. Questionnaires were sent to seventy-nine learners participating in three different online engineering courses, taught by three different instructors. There was a response rate of fifty-four percent (calculation based on the learners who completed the course).

Of the thirty-seven learners who responded to the questionnaires, three held associate degrees, seventeen held bachelor's degrees, ten held master's degrees, three had completed some graduate work and four held Ph.D.s. The length of time learners had worked for the corporation ranged from less than one year to twenty-two years. Learners were distributed across twelve corporate sites and held a variety of job positions, including process engineer, engineering group leader, staff engineer, front-end integration engineer, yield engineer and defect metrology engineer.

Learners enrolled in the online courses for a variety of reasons. The primary reasons were to improve their performance, to achieve a personal goal, and/or to follow a 
recommendation from a manager or colleague. Learners' prior experiences with online education ranged from no prior experience to having completed five or more online courses. The majority of learners had taken one to two prior online education courses.

\section{Procedure and Instrumentation}

Two survey instruments were designed to address the independent and dependent variables: (a) the learner characteristics questionnaire, which addressed participants' demographic profile in terms of years at the corporation, job role, education level, number of online courses previously taken and online self-efficacy; and (b) the learner satisfaction and transfer of learning questionnaire which addressed the online education process and organizational climate variables (such as course design, learner-instructor interaction, learner-learner interaction, collegial support, organizational support, manager support and organizational incentives), and the two dependent variables of learner satisfaction and transfer. In addition, learners responded to two open-ended questions that asked: (a) What contributed most to your learning in this course? and (b) How could this course be improved? Qualitative data included responses from learners to these two openended questions in the survey, and face-to-face and phone interviews with instructors and instructional designers of the courses.

Prior to administration, instruments were reviewed and approved by the COE instructional designers, online staff, and corporate human relations, intellectual property and legal staff. Three distance education experts reviewed the construct validity of the questionnaire items and scales, and their correspondence with the distance education literature. Some of the scales were tested in a previous study conducted by the researchers (Gunawardena, et al. 2005). The questionnaires were developed and 
delivered using Microsoft Word, due to the Corporation's security concerns with online questionnaires. Because of corporate requirements, questionnaires were administered either via e-mail or through the Blackboard Learning Management System, and were collected by the instructor for each of the courses, saved on a thumb drive, and then delivered to the external researchers.

The extensive corporate approval process required for the questionnaires delayed their timely administration, required instructor collection of questionnaires instead of anonymous web-based surveys, and pushed them to be collected amidst a changing organizational climate at a time of restructuring. This impacted the responses to the questions and the number of participants who eventually responded to the questionnaires. There were several cases of missing data where participants did not respond to all items in the two different questionnaires. The corporation was going through major restructuring at the time, and perhaps because of the instability, participants found it difficult to respond to questionnaires about their learning and work environment. Furthermore, because numerous employees were being laid off, existing employees did not have the time to participate in additional activities, such as research. Employees who responded to both questionnaires were included in the research; if an employee did not complete either the first or second questionnaire, s/he was dropped from the study. These factors affected the low response rate to questionnaires. The qualitative data in this mixed methods study compensated for the deficiency presented by the low response rate.

\section{Results and Discussion}

In order to reduce numerical instability in the statistical techniques applied, the quantitative data were reduced using principal components analysis to come up with one 
index variable for each construct. Except where noted, the extraction of the principal components was excellent, with the index explaining between sixty-five and eighty-five percent of the variance of the set of raw scores in most cases. This suggests an overall high level of reliability of the questionnaire and validity of the theoretical constructs.

Answers to the open-ended questions and interviews were analyzed and coded by three researchers who used qualitative content analysis to develop a categorization and coding scheme that emerged from the data.

\section{Learner Satisfaction}

Table 1 presents the reliability summary of the scales used to measure learner satisfaction. The satisfaction scale can be considered very reliable with a Cronbach's alpha of .83. The reliability of the four predictor independent variable scales (online selfefficacy, course design, learner-learner interaction and learner-instructor interaction) was also good. The reliability estimates for these scales with such a small population indicates the strength of these scales for analyzing the variables in this study, except for learnerinstructor interaction which is lower than the other variables (.52). Therefore, the instruments used in this study can be used with confidence in studies with larger populations. The questions for each scale are included in Table 2 .

Table 1: Reliability Summary of Scales Used to Measure Learner Satisfaction

\begin{tabular}{|l|c|c|}
\hline Scales & Number of Items & Cronbach's alpha \\
\hline Online Self-efficacy (I) & 3 & .66 \\
\hline Course Design (I) & 4 & .61 \\
\hline Learner-Learner Interaction (I) & 3 & .69 \\
\hline Learner-Instructor Interaction (I) & 3 & .52 \\
\hline Learner Satisfaction (D) & 5 & .83 \\
\hline
\end{tabular}

I= Independent Variable, D = Dependent Variable 
Table 2: Scales Used to Measure Learner Satisfaction

\begin{tabular}{|c|c|}
\hline Scales - Independent Variables & Dependent Variable \\
\hline $\begin{array}{l}\text { Online Self-efficacy } \\
\text { - I was confident that I could use the technology to } \\
\text { participate in this online course. } \\
\text { - I was able to learn from online course discussions. } \\
\text { - I am confident that I will transfer what I have } \\
\text { learned from an online environment to my work } \\
\text { situation. }\end{array}$ & \multirow{3}{*}{$\begin{array}{l}\text { Learner Satisfaction } \\
\text { - As a result of my } \\
\text { experience in this class, I } \\
\text { would like to participate in } \\
\text { another distance education } \\
\text { course in the future. } \\
\text { - I would recommend this } \\
\text { learning opportunity to } \\
\text { others. } \\
\text { - This class was a useful } \\
\text { learning experience. } \\
\text { - This course met my } \\
\text { expectations. } \\
\text { - I was able to keep up with } \\
\text { the workload. }\end{array}$} \\
\hline $\begin{array}{l}\text { Course Design } \\
\text { - Instructional objectives were clear for me, as a } \\
\text { learner. } \\
\text { - The objectives of this course were clear. } \\
\text { - The teaching materials used in the course improved } \\
\text { my comprehension of the content. } \\
\text { - The course provided clear instructions for all } \\
\text { assignments. }\end{array}$ & \\
\hline $\begin{array}{l}\text { Learner-Instructor Interaction } \\
\text { - All assignments were returned with useful feedback } \\
\text { from the instructor. } \\
\text { - The instructor was easily accessible. } \\
\text { - The instructor responded promptly to my questions. } \\
\text { Learner-Learner Interaction } \\
\text { - Talking to my colleagues at my site who were } \\
\text { - } \text { I waking this course helped me learn. } \\
\text { discussions. } \\
\text { - The diversity of topics discussed prompted me to } \\
\text { participate in the online discussions. }\end{array}$ & \\
\hline
\end{tabular}

Tables 3 and 4 present the results of the regression analysis for learner satisfaction. Multiple regression was used to predict learner satisfaction, using a model with four significant predictor variables: online self-efficacy, course design, learnerlearner interaction, and learner-instructor interaction, ordered by decreasing power, which explained eighty-eight percent of the variance in learner satisfaction. Of these four predictors, online self-efficacy was the highest predictor explaining sixty-three percent of the variance. Course design accounted for fourteen percent of the variance, learner- 
learner interaction accounted for almost seven percent of the variance, and learnerinstructor interaction accounted for two percent of the variance. Therefore, in this analysis, the single best predictor of learner satisfaction with the course is the learner's relative level of confidence and efficacy in working online. Learners who were pleased with and understood the design of the course and experienced a reasonable degree of interaction with the instructor also tended to be satisfied with the course as a whole. Although there were thirty-seven completed questionnaires, the regression analysis was calculated using data from participants who had answered all questions, which totaled only nineteen participants.

Table 3: Learner Satisfaction: Tests of Between-Subjects Effects

\begin{tabular}{|l|c|c|c|c|c|}
\hline \multicolumn{1}{|c|}{ Source } & $\begin{array}{c}\text { Type III Sum } \\
\text { of Squares }\end{array}$ & df & $\begin{array}{c}\text { Mean } \\
\text { Square }\end{array}$ & F & Sig. \\
\hline Corrected Model & $14.002(\mathrm{a})$ & 4 & 3.500 & 26.559 & .000 \\
\hline Intercept & .722 & 1 & .722 & 5.477 & .035 \\
\hline Online Self-efficacy & 3.954 & 1 & 3.954 & 30.000 & .000 \\
\hline Course Design & 1.796 & 1 & 1.796 & 13.630 & .002 \\
\hline Learner-learner Interaction & .540 & 1 & .540 & 4.097 & .062 \\
\hline Learner-instructor Interaction & .378 & 1 & .378 & 2.869 & .112 \\
\hline Error & 1.845 & 14 & .132 & & \\
\hline Total & 16.703 & 19 & & & \\
\hline Corrected Total & 15.847 & 18 & & & \\
\hline
\end{tabular}

R Squared $=.884$ (Adjusted R Squared $=.850$ ) 
Table 4: Model Output for Learner Satisfaction Regression, Parameter Estimates

\begin{tabular}{|c|c|c|c|c|c|c|}
\hline \multirow[b]{2}{*}{ Parameter } & \multirow[b]{2}{*}{ B } & \multirow[b]{2}{*}{$\begin{array}{l}\text { Standard } \\
\text { Error }\end{array}$} & \multirow[b]{2}{*}{$\mathrm{t}$} & \multirow[b]{2}{*}{ Sig. } & \multicolumn{2}{|c|}{$\begin{array}{l}\text { 95\% Confidence } \\
\text { Interval }\end{array}$} \\
\hline & & & & & $\begin{array}{l}\text { Lower } \\
\text { Bound }\end{array}$ & $\begin{array}{l}\text { Upper } \\
\text { Bound }\end{array}$ \\
\hline Intercept & .201 & .086 & 2.340 & .035 & .017 & .386 \\
\hline Online Self-efficacy & .567 & .103 & 5.477 & .000 & .345 & .788 \\
\hline Course Design & .330 & .089 & 3.692 & .002 & .138 & .521 \\
\hline Learner-learner Interaction & -.206 & .102 & -2.024 & .062 & -.425 & .012 \\
\hline $\begin{array}{l}\text { Learner-instructor } \\
\text { Interaction }\end{array}$ & .201 & .118 & 1.694 & .112 & -.053 & .455 \\
\hline
\end{tabular}

Two significant findings arise from the regression analysis. First, an $\mathrm{R}^{2}$ value of 0.884 with only nineteen complete observations is surprising. This means that eightyeight percent of the total variability can be associated with the four factors mentioned above. Such a close relationship between the independent variables and dependent variable is indeed very rare. It is important to point out that the learner-learner interaction index shows a negative sign, indicating that less learner-learner interaction enhances overall learner satisfaction for this population. This may have been due to limited guidance on how to interact with other learners, and the value placed on this type of interaction. It may also be due to the fact that distance learners tend to be more selfdirected, and therefore prefer independence.

Qualitative data shed more light on the quantitative findings. In the quantitative analysis, the significant predictor of learner satisfaction was online self-efficacy, measured by the learner's confidence to use technology to participate in the online course, the ability to learn from online course discussions, and the confidence to transfer learning from the online environment to the workplace. This finding came from a 
population of learners who were technologically savvy and used computers in their dayto-day work. This suggests the importance of orientation to online learning even for students who are technologically savvy. Qualitative data indicated that many learners initially felt they did not need to attend a course orientation due to their familiarity with computers and Internet technologies in their work. However, reasons given for early exits from the course included not being properly informed about the course and its learning management system interface. One learner who did not complete the course said, "[I] did not have experience with some of the applications prior to the class. [There was] not a convenient way to get that training once this class had started." Although the learners were familiar with the individual tools and technology of the course, they were not necessarily knowledgeable about how to participate and learn in an online class.

Other significant predictors of satisfaction were course design factors, learnerinstructor interaction, and learner-learner interaction. Five categories emerged from the open-ended questions as impacting the learning process, including instructional methods, the instructor, organizational support, cultural components such as challenges in being non-native speakers, and online education as a medium for learning.

Learners appreciated when instructors developed a course with clear expectations and guidelines. One learner outlined what she preferred for future online learning classes: "Better communication on what the schedule looks like for due dates and expectations on the final project. There was little guidance given as to what to have and when to have it done". Despite such requests, learners had positive feedback for the instructors, explaining their appreciation of their availability: "Instructors would always stay after to discuss any topic including future materials to be used on the organizational processes". 
Case studies and problem solving activities associated with workplace issues were considered to be one of the most important techniques that helped students transfer their knowledge and skills. One learner explained this sentiment, "The case studies showed good structured problem solving and relevant topics to our everyday work at the organization".

Learners appreciated effective instructional design and delivery. Nevertheless, learners and instructors alike listed challenges that impacted the online learning process. Learners appreciated the flexibility of the online learning environment because it allowed course materials and lessons to be, "viewed later if we could not attend"; however, organizational challenges often impeded learners' ability to participate to the fullest extent. One learner explained this challenge: "It is difficult for engineers to pull people away from projects their managers want done".

Quantitative data showed a negative relationship in learner-learner interaction indicating that the greater the interaction with other learners, the less satisfied the learners were with the course. This was a surprising finding. It could be that the type of learnerlearner interaction that occurred was not conducive to learning. Conversely, qualitative analyses of open-ended participant comments showed that learners wanted increased interaction with instructors and classmates to provide an exchange of ideas and information. One learner suggested the online discussion board be more interactive: "The online bulletin board was a ghost town. I don't know if people asked questions through email or just didn't have many questions, but this could have been a nice resource that I don't think was taken advantage of fully". This lack of interaction between learners could have been due to the instructional context in that learners were not taught how to use 
learner-learner interaction to enhance learning. This finding needs to be investigated further within the organizational context as the organizational culture shapes the learning environment. Conrad (2008) noted that although learners reported engaging and benefiting from participation in a learning community with their online peers, there was little evidence that they contributed to a community of practice in their workplaces. The development of online learning communities that interface with communities of practice in the workplace might be one way to take advantage of the potential of learner-learner interaction in corporate online education. As Homan and Macpherson (2005) predict the utilization of learning and communication technologies in creating local, national or global "communities of learning" is part of the emergent landscape of the corporate university.

\section{Transfer of Learning}

The reliability for the scales used to measure transfer of learning is reported in Table 5. These scales demonstrate good reliability, except for manager support (Cronbach's alpha of .48). We felt that students may not have known how to answer the questions related to manager support as there was considerable missing data in the questionnaires for the items that composed this scale. Given the restructuring that was occurring at the time, students may also have been confused how to respond. We believe that the role of manager support needs to be clarified further for students. It is possible that the questionnaire items we developed for assessing manager support may not have been appropriate. Future research should carefully match the manager's role with questionnaire items. The questions for each scale are included in Table 6 . 
Table 5: Reliability Summary of Scales Used to Measure Transfer of Learning

\begin{tabular}{|l|c|c|}
\hline Scales & Number of Items & Cronbach's (a) \\
\hline Collegial Support (I) & 3 & .90 \\
\hline Organizational Support (I) & 2 & .50 \\
\hline Manager Support (I) & 2 & .48 \\
\hline $\begin{array}{l}\text { Organizational Incentives } \\
\text { (I) }\end{array}$ & 2 & .61 \\
\hline Ability to Transfer (D) & 5 & .62 \\
\hline
\end{tabular}

$\mathrm{I}=$ Independent Variable, $\mathrm{D}=$ Dependent Variable 
Table 6: Scales Used to Measure Transfer of Learning

\begin{tabular}{|l|l|}
\hline Scales: Independent Variables & Dependent Variable \\
\hline Collegial Support & Ability to Transfer \\
\hline
\end{tabular}

- My colleagues encourage me to implement what I have learned in this course.

- I share what I have learned with my colleagues so that more employees benefit from my learning opportunities.

- I have worked together with my colleagues in troubleshooting complications when implementing the newly-acquired skills.

\section{Organizational Support}

- The resources that I need to apply my learning are available to me.

- My workload has allowed me time to try out my new learning.

\section{Manager Support}

- My manager and I set goals for improving my job skills through this course.

- My manager has provided me with opportunities to use the skills I have learned.

\section{Organizational Incentives}

- My organization will reward me if I apply newly learned skills successfully.

- The rewards I receive when I successfully apply what I learn will be worthwhile for me.

Tables 7 and 8 present the results of the regression analysis for the ability to transfer learning to the workplace. Four independent predictor variables that measured organizational climate - collegial support, organizational support, manager support and organizational incentives were used to predict the dependent variable of transfer of learning. Modeling the ability of the participants to transfer their learning to the workplace, using forward and backward stepwise variable selections converged on a set of two significant predictor variables, collegial support and organizational support for transfer. This model attained an $\mathrm{R}^{2}$ value of 0.502 , showing that higher perceived levels of collegial and organizational support for transfer result in higher perceived ability to 
transfer learning to the workplace. Results indicate that more than forty-five percent of the variance in learners' ability to transfer learning is explained by collegial support, making it a high predictor of the learners' ability to transfer learning to the workplace.

Table 7: Transfer of Learning: Tests of Between-Subjects Effects

\begin{tabular}{|l|c|c|c|c|c|}
\hline \multicolumn{1}{|c|}{ Source } & $\begin{array}{c}\text { Type III Sum of } \\
\text { Squares }\end{array}$ & df & $\begin{array}{c}\text { Mean } \\
\text { Square }\end{array}$ & $\mathrm{F}$ & Sig. \\
\hline Corrected Model & $16.107(\mathrm{a})$ & 2 & 8.053 & 16.235 & .000 \\
\hline Intercept & .002 & 1 & .002 & .003 & .955 \\
\hline Collegial Support & 6.815 & 1 & 6.815 & 13.739 & .001 \\
\hline $\begin{array}{l}\text { Organizational } \\
\text { Support }\end{array}$ & 2.371 & 1 & 2.371 & 4.780 & .037 \\
\hline Error & 13.890 & 28 & .496 & & \\
\hline Total & 30.004 & 31 & & & \\
\hline Corrected Total & 29.996 & 30 & & & \\
\hline
\end{tabular}

a R Squared $=.537$ (Adjusted R Squared $=.504)$

Table 8: Model Output for Transfer Regression: Parameter Estimates

\begin{tabular}{|l|c|c|c|c|c|c|}
\hline \multicolumn{1}{|c|}{ Parameter } & $\mathrm{B}$ & $\begin{array}{c}\text { Standard } \\
\text { Error }\end{array}$ & $\mathrm{t}$ & $\mathrm{Sig}$. & \multicolumn{2}{|c|}{$\begin{array}{c}\text { 95\% Confidence } \\
\text { Interval }\end{array}$} \\
\hline & & & & & $\begin{array}{c}\text { Lower } \\
\text { Bound }\end{array}$ & $\begin{array}{c}\text { Upper } \\
\text { Bound }\end{array}$ \\
\hline Intercept & -.007 & .127 & -.057 & .955 & -.266 & .252 \\
\hline Collegial Support & .541 & .146 & 3.707 & .001 & .242 & .840 \\
\hline $\begin{array}{l}\text { Organizational } \\
\text { Support }\end{array}$ & .294 & .135 & 2.186 & .037 & .019 & .570 \\
\hline
\end{tabular}

The highest predictor of transfer of learning to the workplace was collegial support, which shows the necessity for an organizational culture to promote collegiality when new learning is transferred. Qualitative data revealed deeper insights into transfer of learning and provided specific examples of how this transfer occurred. For example, 
one learner mentioned how an online discussion provided him/her with a greater familiarity with how other locations solved problems in the factory. He said, "It was very interesting and enlightening to see how other teams successfully applied the skills and principles covered in this course". This supplied the learner with important knowledge that could be applied back on the job, thus improving the local production times. Overall, learners were positive about the ability to transfer in the open-ended responses. One learner expressed this sentiment in the following quote: "The material taught... was very helpful, and in the long run, will save time in my job".

Learners most appreciated when class and homework questions required students to observe processes in the factory and report on them. One instructor requested that his learners: "explain to me what you see." This required the students who would usually work at computers to go down into the basement and observe how processes were managed by different employees, how the pipes sounded, and how the technology in the factory worked.

Overall, the learners felt they had the resources that they needed to transfer their learning. However, they explained that it would be easier to transfer if there was more managerial support. Learners expressed feeling overwhelmed by course and work requirements: "It was very well done, just difficult to keep up with at times due to job constraints. I suspect that management also forgot / wasn't continuously aware that I was in this class, and felt that I should be doing more of my regular activities". This learner felt pressure to focus on work, rather than on his studies which may have provided him the opportunity to transfer new learning. The learners who reported being able to transfer the learning had worked with their managers to set goals to implement what they had 
learned. This is a key factor to keep in mind when designing future corporate distance education programs.

\section{Challenges of a Corporate Online Education Program}

During face-to-face and phone interviews, the instructors and instructional designers of the courses studied provided input on their perspectives of the online courses and the challenges that they encountered. Several instructors and instructional designers mentioned that the scope of and expectations for the online courses kept changing, which left them unsure about course expectations and outcomes. One instructor suggested that organizational support was a predictor of transfer. He recommended that the instructional designers demonstrate the necessity for connecting the educational initiative to the corporation's strategic plan, thus providing support and funding. Instructors and instructional designers alike echoed the learners when they stated that a critical component of the success of a corporate distance education program is a project manager who understands the technical area.

Similar to learner perspectives, the instructors interviewed pointed out that the priority in a corporate setting was to solve technical problems within the plant, and not further education. Technical emergencies had to be given priority and were typically the cause of early exits and limited participation throughout the courses. Berge (2007) echoed this view when he said that time to attend to personal skill development while concurrently needing to attend to business deliverables often seems impossible in corporate distance education. This is one of the disadvantages of holding synchronous online learning classes during company work time. This further impeded the ability for learners to transfer what they had learned in class. 
Lack of enforcement of course pre-requisites created difficulties for both learners and instructors due to the variety of skill sets present in the courses. Establishing and marketing clear course expectations would help learners make informed decisions regarding enrollment and position them to better meet course and instructor expectations and course outcomes. The COE must consider offering more courses in asynchronous modes and archiving synchronous class sessions for review. Since learners and instructors are engaged in technical work, they depend on a flexible learning environment. Pre-requisites and scheduling are important considerations so that learners are well prepared to meet course expectations.

One of the instructors also explained the challenges faced by some learners who are not native speakers of English. He felt the language, and especially the technical jargon impeded their learning and contributions to the learning community. In multinational corporations, culture and language need to be a constant consideration during course design and development (Parrish and Linder-VanBerschot 2010).

\section{Conclusions and Implications for Future Research}

Learners, instructors and instructional designers perceived online education as a viable means of updating knowledge and skills in an international corporate online program. This study showed that technical problem-solving skills can be developed using online teaching methods. The highest predictor of learner satisfaction in the courses was online self-efficacy, suggesting the importance of orientation programs for corporate employees who are new to online learning even though they may be technically savvy. This echoes Lim's (2001) finding that self-efficacy was the only statistically significant variable that predicted learner's intent to participate in future web-based courses. The 
finding also supports Ong, Lai and Wang's (2004) study, which reported that computer self-efficacy was the most significant factor affecting user's acceptance of online education in high-tech companies. It would be interesting in a future research study to explore changes in perceived self-efficacy before and after online courses.

The highest predictor of transfer of learning to the workplace was collegial support, which demonstrates the necessity for an organizational culture that encourages peer support for transfer of new learning. Similarly, Burke and Hutchins (2007) established that the most consistent factor explaining the relationship between the work environment and transfer of training was the support a trainee receives from both peers and supervisors. Qualitative data outlined the advantages and challenges to online education in corporate settings, with instructional methods and instructor characteristics being the primary positive impacts.

In reviewing the methods and analyses used in this mixed-methods study, the qualitative data yielded information of great value, enhancing the quantitative data gathered from the small sample size. We also learned about the challenges of conducting research in a large organization that was undergoing restructuring. The custom-designed research instruments developed for this study held well despite the small sample size. Future use of these instruments with larger populations is recommended.

The major limitation of this study was the small sample size. This was due to the uncertain organizational climate; learners may have been worried about honestly reporting their perceptions. Non-response bias is a concern in this study. Relationships that exist in the data could have easily been missed because of the low power of the techniques applied for small sample sizes. This may also explain the extremely 
remarkable correlation between learner satisfaction and the four independent variables: online self-efficacy, course design, learner-instructor interaction, and learner-learner interaction. However, the scales held well, and we were able to derive results from this small sample size that are of value. In general, the relative importance of the predictor variables in the learner satisfaction and transfer studies seems reasonable given the strong reliability of the scales used. The qualitative data provided the necessary information to fill in the gaps due to the small sample size.

From this study we were able to derive implications for researching transfer of training in future studies. We felt that while satisfaction can be measured at the end of a course, true assessment of transfer needs a minimum of six months. We feel that time series analyses where we can make many repeated measurements on the same individual and organization may yield more useful results when studying transfer from a quantitative perspective. We also feel that rather than measuring self perceptions of transfer through surveys, transfer should be measured by self ranking and manager ranking on ability to perform a certain task if the corporate climate allows it. Interviews conducted with both learners and peers for changes in performance would provide useful evidence as well. Lobato (2008) has noted how research methods influence the way transfer is studied. In the corporate context, a transfer of learning model should incorporate prior experiences of learners to determine the extent of transfer.

This study moved online education research in corporate settings beyond descriptive case studies to understanding factors that promote learner satisfaction and transfer of learning. Even though the sample size is small, with reliable instruments and a mixed methods design, this study provides a framework for designing online education 
research studies in corporate settings in the future.

Online education can become a catalyst for organizational learning and growth by training employees in work-related problem solving at national and international corporate sites. The impact of online education will be dependent on how it is adopted and used within organizational contexts, and how well it supports the objectives, strategies and values of learning within a corporate university.

\section{REFERENCES}

Abrami, P. C., and R. M. Bernard. 2006. Research on distance education: In defense of field experiments. Distance Education 27 (1):5-26.

Allen, M., N. Burrell, J. Bourhis, and E. Timmerman. 2007. "Literature of satisfaction." In Handbook of Distance Education (Second Edition), edited by M. G. Moore, 149-156. Mahwah, New Jersey: Lawrence Erlbaum Associates, Inc.

Arbaugh, J. B., and S. R. Hiltz. 2005. "Improving quantitative research on ALN effectiveness." In Learning together online: Research on asynchronous learning networks, edited by S. R. Hiltz and R. Goldman, 81-102. Mahwah, NJ: Lawrence Erlbaum Associates, Inc.

Baldwin, T. T., and J. K. Ford. 1988. Transfer of training: A review and directions for future research. Personal Psychology 41 (1):63-105.

Bandura, A. 1995. Self-efficacy in changing societies. New York City: Cambridge University Press.

Belanich, J., R. A. Wisher, and K. L. Orvis. 2004. A question-collaboration approach to 
web-based learning. The American Journal of Distance Education, 18 (3): 169185.

Berge, Z. L. 2007. Training in the corporate sector. In Handbook of Distance Education (Second Edition), edited by M. G. Moore 515-529. Mahwah, New Jersey: Lawrence Erlbaum Associates, Inc.

Burke, L. A., and H. M. Hutchins. 2007. Training transfer: An integrative literature review. Human Resource Development Review 6 (3):263-296.

Conrad, D. L. 2008. From community to community of practice: Exploring the connection of online Learners to informal learning in the workplace. The American Journal of Distance Education. 22 (1): 3-23.

Creswell, J. W., and V. L. P. Clark. 2007. Designing and conducting mixed methods research. Thousand Oaks, CA: Sage Publications.

DeTure, M. 2004. Cognitive style and self-efficacy: Predicting student success in online distance education. The American Journal of Distance Education. 18 (1): 21-38.

Dobrovolny, J. 2006. How adults learn from self-paced, technology-based corporate training: New focus for learners, new focus for designers. Distance Education. 27 (2): $155-170$.

Garrison, D. R., and M. Cleveland-Innes. 2005. Facilitating cognitive presence in online learning: Interaction is not enough. The American Journal of Distance Education. 19 (3): 133-148.

Goldman, R., M. Crosby, K. Swan, and P. Shea. 2005. "Qualitative and quisitive research methods for describing online learning." In Learning together online: Research 
on asynchronous learning networks, edited by S. R. Hiltz and R. Goldman, 103120. Mahwah, NJ: Lawrence Erlbaum Associates, Inc.

Gunawardena, C. N., P Boverie, P. Ahonen,. P. L Wilson,. L. Ortegano-Layne, \& K. Barrett. 2005. Evaluation of the Oklahoma State University HbL4u Project Year 5 Report (Study funded by the U.S. Department of Education, Office of Educational Research and Improvement, Grant No. R203f000039). Albuquerque, NM: University of New Mexico, Organizational Learning and Instructional Technology Program.

Holton, E. F. 1996. The flawed four-level evaluation model. Human Resource Development Quarterly, 7 (1):5-25.

Holton, E. F. III, R. A. Bates and W. E. A. Ruona. 2000. Development and construct validation of a generalized learning transfer system inventory. Human Resource Development Quarterly. 11 (4): 333-360.

Homan, G., and A. Macpherson. 2005. E-learning in the corporate university. Journal of European Industrial Training. 29 (1): 75-90.

Juwah. C., ed., 2006. Interactions in online education: Implications for theory and practice. New York: Routledge

LaPointe, D. K., and C. N. Gunawardena. 2004. Developing, testing and refining of a model to understand the relationship between peer interaction and learning outcomes in computer-mediated conferencing. Distance Education 25 (1): 83106.

Lim, C. K. 2001. Computer self-efficacy, academic self-concept, and other predictors of satisfaction and future participation of adult distance learners. The American 
Journal of Distance Education 15 (2): 41-51.

Lim, D. H. and M. L. Morris. 2006. Influence of trainee characteristics, instructional satisfaction, and organizational climate on perceived learning and training transfer. Human Resource Development Quarterly. 17 (1). 85-115.

Lobato, J. 2008. "Research Methods for Alternative Approaches to Transfer: Implications for Design Experiments.” In Handbook of Design Research Methods in Education, edited by A. Kelly, R. A. Lesh, and J. Y. Baek, 167-194. New York: Routledge.

Macdonald, I. S., M. Bullen, R. Kozak. 2007. Identifying effective pedagogical approaches for online workplace training: A case study of the South African wood products manufacturing sector. International Review of Research in Open and Distance Learning, 8 (3): http://www.irrodl.org/index.php/irrodl/article/view/400/936 (accessed August 4, 2010).

Moore, M. G. 2006. Editorial: Stages of organizational capability. The American Journal of Distance Education. 20 (4): 191-193.

Ong, C. S., J.Y. Lai, and Y.S. Wang. 2004. Factor's affecting engineers' acceptance of asynchronous e-learning systems in high-tech companies. Information \& Management, 41: 795-804.

Park, J. H., and T. Wentling. 2007. Factors associated with transfer of training in workplace eLearning. Journal of Workplace Learning. 19 (5): 311-329. 
Parrish, P. and J. A. Linder-VanBerschot. 2010. Cultural dimensions of learning: Addressing the challenges of multicultural instruction. International Review of Research in Open and Distance Learning. 11 (2): http://www.irrodl.org/index.php/irrodl/article/view/809 (accessed July 31, 2010).

Puzziferro, M. 2008. Online technologies self-efficacy and self-regulated learning as predictors of final grade and satisfaction in college-level online courses. The American Journal of Distance Education. 22 (2): 72-89.

Rabak, L, \& M. Cleveland-Innes. 2006. Acceptance and resistance to corporate elearning: A case study from the retail sector. The Journal of Distance Education, 21 (2): http://www.jofde.ca/index.php/jde/article/view/59 (accessed August 4, 2010).

Rhode, J. F. 2009. Interaction equivalency in self-paced online learning environments: An exploration of learner preferences. International Review of Research in Open and Distance Learning. 10 (1): http://www.irrodl.org/index.php/irrodl/article/view/603/1178 (accessed August 31, 2010).

Wang, A., and M. Newlin. 2002. Predictors of Web-student performance: The role of self-efficacy and reasons for taking an online class. Computers in Human behavior 18: 151-163. 
